\title{
ConTrole Químico da Tiririca (Cyperus rotundus), Com E SEM Cobertura do Solo pela Palha de Cana-De-Açúcar ${ }^{1}$
}

\author{
Chemical Control of Cyperus rotundus, With and Without Sugar Cane Straw Cover \\ DURIGAN, J.C. ${ }^{2}$, TIMOSSI, P.C. ${ }^{3}$ e LEITE, G.J. ${ }^{4}$
}

\begin{abstract}
RESUMO - Objetivou-se neste trabalho avaliar a eficácia e seletividade da mistura comercial pronta de trifloxysulfuron-sodium + ametryne $\left(1.312,5\right.$ e $\left.1.500 \mathrm{~g} \mathrm{ha}^{-1}\right)$, em comparação ao halosulfuron (112,5 $\left.\mathrm{g} \mathrm{ha}^{-1}\right)$, MSMA (2.400 $\left.\mathrm{g} \mathrm{ha}^{-1}\right), 2$, 4-D (1.675 $\left.\mathrm{g} \mathrm{ha}^{-1}\right)$, sulfentrazone (700 $\left.\mathrm{g} \mathrm{ha}^{-1}\right)$ e imazapic (105 $\left.\mathrm{g} \mathrm{ha}^{-1}\right)$, além das testemunhas infestada e capinada, no controle de tiririca (Cyperus rotundus) em um canavial, com e sem cobertura do solo com a palhada da cana remanescente da colheita. A palhada de cana reduziu a infestação, porém não evitou grandes densidades das plantas de tiririca. O número de tubérculos inviáveis foi superior a $50 \%$ nas áreas onde se aplicou a mistura pronta $\left(1.312,5\right.$ e $\left.1.500 \mathrm{~g} \mathrm{ha}^{-1}\right)$, apesar do controle apenas regular $(41,3$ a $67,5 \%)$ das manifestações epígeas. Os melhores resultados de controle foram proporcionados pelos herbicidas sulfentrazone $\left(700 \mathrm{~g} \mathrm{ha}^{-1}\right)$ e imazapic $\left(105 \mathrm{~g} \mathrm{ha}^{-1}\right)$, sem a cobertura de palha. O número de afilhos, a altura das plantas e a produção de colmos foram reduzidos apenas na testemunha infestada e onde se aplicaram os herbicidas 2,4-D (1.675 $\left.\mathrm{g} \mathrm{ha}^{-1}\right)$ e MSMA (2.400 $\left.\mathrm{g} \mathrm{ha}^{-1}\right)$, que proporcionaram os menores niveis de controle. Os herbicidas foram seletivos para as plantas de cana-de-açúcar da variedade RB806043.
\end{abstract}

Palavras-chave: Sacharum officinarum, cobertura morta, herbicidas, pós-emergência.

ABSTRACT - The experiment was carried out to test the efficacy of trifloxysulfuron-sodium + ametryne (1,312.5 and 1,500 $\mathrm{g} \mathrm{ha}$ ), as compared to halosulfuron (112.5 $\mathrm{g} \mathrm{ha}$ ), MSMA $(2,400 \mathrm{~g} \mathrm{ha}), 2,4-D\left(1,675 \mathrm{~g} \mathrm{ha}{ }^{1}\right)$, sulfentrazone (700 $\left.\mathrm{g} \mathrm{ha}{ }^{1}\right)$ and imazapic (105 $\left.\mathrm{g} \mathrm{ha}{ }^{1}\right)$, as well as the checks, with and without weeds, to control Cyperus rotundus in sugarcane (cultivar RB806043), in a field area, with and without sugarcane straw cover. Although sugarcane coverdecreased weed infestation it did not provide acceptable control of C. rotundus plants. The percentage of unviable tubers was superior to $50 \%$ in areas where trifloxysulfuron-sodium + ametryne (1,312.5 and 1,500 $\left.\mathrm{g} \mathrm{ha}^{1}\right)$ was applied in spite of regular shoot number control (41.3\% to 67.5\%). The best control was obtained with sulfentrazone $\left(700 \mathrm{~g} \mathrm{ha}^{1}\right)$ and imazapic (105 $\mathrm{g} \mathrm{ha}$ ) applications without straw cover. Shoot number, plant height and straw yield were reduced only in the infested check and with application of 2,4-D (1,675 $\left.\mathrm{g} \mathrm{ha} \mathrm{h}^{1}\right)$ and MSMA $\left(2,400 \mathrm{~g} \mathrm{ha} \mathrm{a}^{1}\right)$, which showed the lowest control levels. The herbicides were selective for the sugarcane cultivar RB806043.

Key words: Sacharum officinarum, mulching, herbicides, post-emergence.

\section{INTRODUÇÃO}

Estima-se que cerca de 1.000 espécies de plantas daninhas habitem o agroecossistema da cana-de-açúcar, nas distintas regiões produtoras do mundo (Arevalo, 1979).
As condições microclimáticas e de manejo, predominantes em um canavial, permitem o estabelecimento de flora infestante, considerada daninha, relativamente específica e bem característica. A colheita da cana-deaçúcar sem a tradicional queimada deixa

Recebido para publicação em 6.8.2003 e na forma revisada em 5.3.2004.

Professor Titular do Departamento de Fitossanidade da FCAV, Campus de Jaboticabal, Universidade Estadual Paulista UNESP. Via de acesso Paulo Donato Castellane, s/n, 14884-900 Jaboticabal-SP, <jdurigan@fcav.unesp.br >; ${ }^{3}$ Doutorando em Produção Vegetal na área de Matologia - FCAV-UNESP, <ptimossi@fcav.unesp.br >; ${ }^{4}$ Técnico Agrícola do Dep. de Fitossanidade - FCAV-UNESP. 
sobre o solo uma espessa camada de palha, que pode superar $20 \mathrm{t} \mathrm{ha}^{-1}$, e, juntamente com as modificações técnicas necessárias para se implementar a colheita mecânica, cria um novo sistema de produção, popularizado como cana crua (Velini \& Negrisoli, 2000).

Martins et al. (1999) estudaram os efeitos da cobertura com diferentes quantidades de palha sobre a germinação das principais espécies de plantas daninhas da cana-de-açúcar no Brasil. Algumas espécies tiveram a germinação suprimida, enquanto outras foram indiferentes ou até estimuladas. De modo coerente com essas informações, drásticas reduções na incidência de gramíneas são observadas em áreas de cana crua. Por outro lado, altas infestações de Euphorbia heterophylla e Ipomoea spp. têm sido constatadas nessas áreas.

Especificamente para a tiririca, é falsa a impressão de que a barreira de palha possa inibir totalmente a sua brotação e a formação de manifestações epígeas. Pesquisas precisam ser realizadas para a elucidação das alterações que sofrerá esta espécie, em função da mudança no sistema de produção. Da mesma forma, é necessário conhecer a ação dos herbicidas, sobretudo aqueles aplicados em pré-emergência, para o seu controle, comparando-se com a situação tradicional. Segundo Velini \& Negrisoli (2000), para uma camada de palha de $1 \mathrm{t} \mathrm{ha}^{-1}$, apenas 35,5\% da calda pulverizada atinge o solo. Essa interceptação atinge 99,4 e $99,5 \%$, para 10 e $15 \mathrm{t} \mathrm{ha}^{-1}$, respectivamente.

No presente trabalho, objetivou-se avaliar o controle químico da tiririca, com a mistura pronta de trifloxysulfuron-sodium + ametryne, em comparação a outros herbicidas recomendados e aplicados em pré e pós-emergência, considerando as condições de crescimento com e sem cobertura de palha das plantas de canade-açúcar remanescentes do cultivo anterior.

\section{MATERIAL E MÉTODOS}

O experimento foi instalado e conduzido no município de Jaboticabal, SP, em área da Usina São Carlos, durante o ano agrícola de 2000/01. O solo do local foi classificado como Latossol Roxo, com classe textural barro-argilosa, $\mathrm{pH}$ em $\mathrm{CaCl}_{2}$ de 5,9, CTC de $81,7 \mathrm{mmol}_{\mathrm{c}} \mathrm{dm}^{-3}$ e saturação por bases de $70 \%$.
O delineamento experimental foi em blocos casualizados, com parcelas subdivididas e cinco repetições. Foram considerados como parcelas os tratamentos herbicidas aplicados em pós-emergência (trifloxysulfuron-sodium + ametryne a $1.312,5$ e $1.500 \mathrm{~g} \mathrm{ha}^{-1}$, halosulfuron + surfatante a $112,5 \mathrm{~g} \mathrm{ha}^{-1}+0,25 \% \mathrm{v} / \mathrm{v}$, MSMA a $2.400 \mathrm{~g} \mathrm{ha}^{-1}$ e o $2,4-\mathrm{D}$ a $1.675 \mathrm{~g} \mathrm{ha}^{-1}$ ) e em pré-emergência (sulfentrazone a $700 \mathrm{~g} \mathrm{ha}^{-1} \mathrm{e}$ imazapic a $105 \mathrm{~g} \mathrm{ha}^{-1}$ ), juntamente com as testemunhas infestada e capinada. As subparcelas foram constituídas da presença e da ausência de palha sobre o solo. As parcelas continham cinco linhas, espaçadas de 1,4 m e com 14,0 m de comprimento, sendo a metade $(7,0 \mathrm{~m})$ mantida com cobertura de palha, na quantidade equivalente a $10 \mathrm{t} \mathrm{ha}^{-1}$, e na outra metade a palha foi totalmente retirada da área. A área total das parcelas foi de $98,0 \mathrm{~m}^{2}$ e a das subparcelas, de 49,0 $\mathrm{m}^{2}$. A área útil, em cada subparcela, era de $25,2 \mathrm{~m}^{2}$, considerando-se as três linhas centrais com 6,0 de comprimento. A variedade de cana-de-açúcar utilizada foi a RB 806043.

A aplicação dos herbicidas foi feita com solo úmido, entre $9 \mathrm{~h} 10$ e $11 \mathrm{~h} 30$ minutos. Utilizou-se pulverizador costal à pressão constante (mantida por ar comprimido) de 2,4 $1 \mathrm{bf} \mathrm{cm}^{-2}$, munido de barra com seis bicos de jato plano DG 11002 , espaçados de $0,5 \mathrm{~m}$, proporcionando consumo de calda equivalente a $200 \mathrm{~L} \mathrm{ha}^{-1}$. No momento da aplicação dos herbicidas em pós-emergência, a temperatura ambiente era de $30{ }^{\circ} \mathrm{C}$, a UR de $70 \%$, a temperatura do solo (a $5 \mathrm{~cm}$ de profundidade) era de $24{ }^{\circ} \mathrm{C}$, a nebulosidade de $95 \%$ e os ventos, com velocidades variáveis de 3 a $5 \mathrm{~km} \mathrm{~h}^{-1}$. As plantas de cana-deaçúcar estavam com 0,40 a $0,50 \mathrm{~m}$ de altura, no estádio de três a cinco folhas, e as de tiririca, com cerca de $0,25 \mathrm{~m}$ de altura e de seis a oito folhas. Nos tratamentos em pré-emergência, houve necessidade de remover a palha e realizar a capina, com o mínimo revolvimento do solo, eliminando as manifestações epígeas de tiririca. Logo após a aplicação, a palha foi esparramada novamente.

Foram avaliados o número de manifestações epígeas por $\mathrm{m}^{2}$, em todas as subparcelas, um dia antes das aplicações em pré e pósemergência e aos 45 e 90 dias após a aplicação (DAA), para avaliação da eficácia dos herbicidas. Para isso, foram feitas cinco 
amostragens, ao acaso, com retângulo de $0,20 \times 0,50 \mathrm{~m}$, totalizando $0,5 \mathrm{~m}^{2}$, por subparcela. As porcentagens de controle foram calculadas em relação à testemunha infestada, com e sem palha. As avaliações visuais dos sintomas de intoxicação, constatados nas plantas de cana-de-açúcar, foram feitas aos 7 , 30 e 60 DAA por três avaliadores, com base na escala de notas do EWRC (1964).

O efeito dos herbicidas e da interferência das plantas daninhas remanescentes no número de afilhos da cana foram avaliados aos $60 \mathrm{DAA}$, em $2 \mathrm{~m}$ de cada linha da área útil da subparcela, totalizando $6 \mathrm{~m}$. Nesta mesma data, mediu-se a altura das plantas até a última aurícula visível, do colo para o ápice, em 10 plantas seguidas, de uma das linhas.

O número de tubérculos foi avaliado aos 65 DAA, em um volume de $0,027 \mathrm{~m}^{3}$ de solo, com amostras de $0,30 \times 0,30 \times 0,30 \mathrm{~m}$ por subparcela. O solo foi peneirado e os tubérculos separados, contados e armazenados em sacos plásticos. Do total de tubérculos por subparcela, separaram-se 50 deles, ao acaso, para a determinação do número e das respectivas porcentagens de viáveis, inviáveis e dormentes. Esse lote de tubérculos foi colocado inicialmente, sem serem lavados, para brotar, em toalhas de papel umedecidas com água destilada, sobre bandejas, por um período de 10 dias, sendo mantidos à temperatura de 25$28{ }^{\circ} \mathrm{C}$, em germinador. Após esse período, os tubérculos brotados (viáveis) foram contados, separando-os dos demais. Para conhecer a quantidade de tubérculos dormentes e, conseqüentemente, dos inviáveis (podres e afetados pelos herbicidas) desse lote restante, estes foram submetidos ao teste do tetrazólio, segundo metodologia proposta por Delouche et al. (1962).

Por ocasião da colheita, feita no dia 13/ 08/2001, contou-se o número de colmos em toda a extensão $(7 \mathrm{~m})$ das três linhas centrais, perfazendo $21 \mathrm{~m}$ por subparcela. O total de colmos, colhido nas três linhas centrais de cada subparcela, ou em $29,4 \mathrm{~m}^{2}$, foi pesado e os resultados extrapolados e expressos em toneladas por ha. Posteriormente, foram enviados para a realização das análises tecnológicas de rotina (Brix, Pol cana e caldo, Acidez, Pureza, Fibra e ATR).
Os dados foram submetidos à análise de variância, sendo as médias comparadas pelo teste de Tukey, a 5\% de probabilidade. As análises foram realizadas no programa ESTAT do Departamento de Ciências Exatas da FCAV/UNESP. Quando as interações foram significativas, procedeu-se ao seu desdobramento.

\section{RESULTADOS E DISCUSSÃO}

Os diferentes herbicidas testados mostraram-se pouco tóxicos às plantas de canade-açúcar, como pode ser observado pelas notas atribuídas para as três épocas, após a aplicação (Tabela 1). Com exceção do MSMA, que foi responsável pela formação de manchas necróticas nos locais em que atingiu as folhas de cana, detectadas desde a primeira avaliação, e do imazapic, que, além de leve clorose generalizada, conferiu ligeira redução no crescimento inicial das plantas, todos os demais herbicidas foram seletivos para a variedade (RB 806043). Além disso, apesar da injúria inicial, os sintomas desapareceram gradualmente nas avaliações feitas aos 30 e 60 DAA, com a emissão de folhas novas, totalmente isentas de tais problemas.

O número de manifestações epígeas da tiririca na área experimental, antes da aplicação dos herbicidas, foi reduzido pela cobertura com palha, conforme mostra a análise de variância da Tabela 2 . Pode-se constatar que também houve interação significativa entre os herbicidas e a cobertura vegetal nas avaliações realizadas aos 45 e 90 dias após a aplicação. Os desdobramentos destas interações são apresentados na Tabela 3 .

A palha reduziu em 47,8 e $19,5 \%$ o número de manifestações epígeas por $\mathrm{m}^{2}$, aos $45 \mathrm{e}$ 90 DAA, respectivamente, mostrando ser forte aliada no controle, mas está longe de ser a solução para evitar a brotação, emergência e convivência da tiririca com a cultura. Ainda são escassas as pesquisas com o efeito da palha de cana sobre a infestação de plantas daninhas, porém vários estudos têm comprovado a eficácia de outros tipos de cobertura vegetal nessa redução (Fornarolli et al., 1998; Martins et al., 1999).

Planta Daninha, Viçosa-MG, v.22, n.1, p.127-135, 2004 
Tabela 1 - Médias das notas visuais dos sintomas de intoxicação nas plantas de cana-de-açúcar, aos 7, 30 e 60 dias após a aplicação (DAA) dos herbicidas, com base na escala EWRC (1964). Jaboticabal-SP, 2000/2001

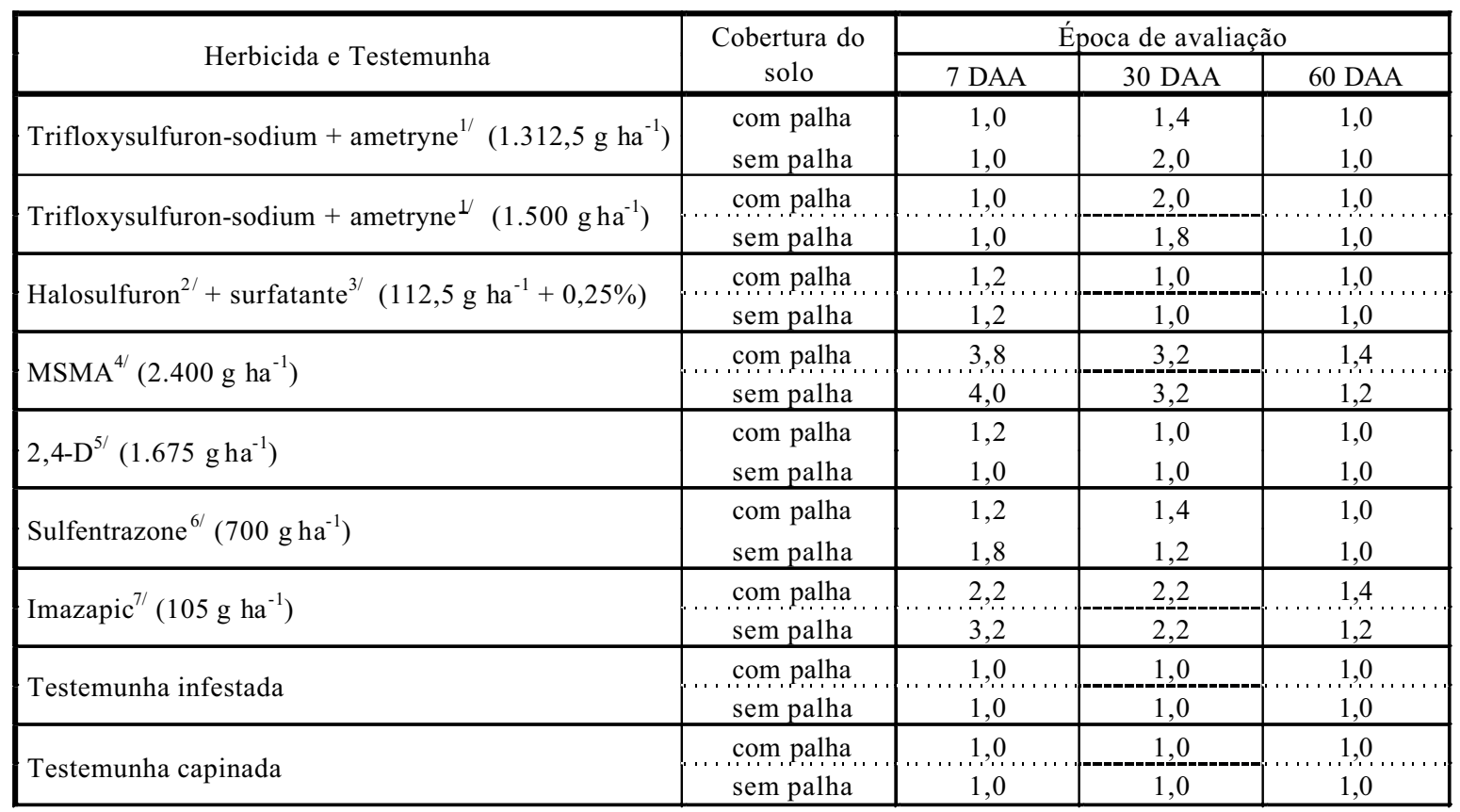

${ }^{1 /}$ Krismat; ${ }^{2 /}$ Sempra; ${ }^{3 /}$ Aterbane; ${ }^{4 /}$ Daconate; ${ }^{5 /}$ Aminol; ${ }^{6 /}$ Boral; e ${ }^{7 /}$ Plateau.

Tabela 2 - Análise da variância do número de manifestações epígeas de tiririca por $\mathrm{m}^{2}$ antes da aplicação dos herbicidas e aos 45 e 90 dias após, além do teste (Tukey) de comparação das médias quando não houve interação significativa entre os fatores. Jabot icabal-SP, 2000/2001

\begin{tabular}{|c|c|c|c|}
\hline \multirow{3}{*}{ Causa da variação } & \multicolumn{3}{|c|}{ Valor de F } \\
\hline & \multirow{2}{*}{$\begin{array}{c}\mathrm{N}^{\mathrm{o}} \text { manif. epígeas } \mathrm{m}^{-2} \\
\text { antes aplicação }\end{array}$} & \multicolumn{2}{|c|}{ Controle } \\
\hline & & $45 \mathrm{DAA}$ & 90 DAA \\
\hline Cobertura (C) & $396,99^{* *}$ & $119,28^{* *}$ & $0,0^{\mathrm{ns}}$ \\
\hline Herb. x Cob. $(\mathrm{H} \times \mathrm{C})$ & $0,25^{\mathrm{ns}}$ & $36,74^{* * \cdots}$ & 15,35 \\
\hline $\mathrm{CV}(\%)$ & $10,6(\mathrm{H}) \quad 12,2(\mathrm{C})$ & $18,1(\mathrm{H}) \quad 17,4(\mathrm{C})$ & $17,6(\mathrm{H}) \quad 20,4(\mathrm{C})$ \\
\hline Trifloxysulfuron-sodium + ametryne $\left(1.500 \mathrm{~g} \mathrm{ha}^{-1}\right) \ldots$ & 461,7 & & \\
\hline Halosulfuron ${ }^{2}+$ surfatante $^{3 /}\left(112,5 \mathrm{~g} \mathrm{ha}^{-1}+0,25 \%\right)$ & 507,4 & & \\
\hline MSMA $^{4 /}\left(2400 \mathrm{~g}^{-1}\right)$ & . 523,2 & & \\
\hline $2,4-D^{5 /}\left(1.675 \mathrm{~g} \mathrm{ha}^{-1}\right)$ & (n) & & \\
\hline Sulfentrazone $^{6 /}\left(700 \mathrm{~g} \mathrm{ha}^{-1}\right)$ & '523,4 & & \\
\hline dms a $5 \%$ & 80,7 & & \\
\hline Cobertura com palha & $381,0 \mathrm{~b}$ & & \\
\hline Cobertura sem palha & & & \\
\hline $\mathrm{dms}$ a $5 \%$ & 26,8 & & \\
\hline
\end{tabular}

${ }^{1 /}$ Krismat; ${ }^{2 /}$ Sempra; ${ }^{3 /}$ Aterbane; ${ }^{4 /}$ Daconate; ${ }^{5 /}$ Aminol; ${ }^{6 /}$ Boral; e ${ }^{7 /}$ Plateau. 
Tabela 3 - Médias do número de manifestações epígeas de tiririca por $\mathrm{m}^{2}$, aos 45 e 90 dias após a aplicação (DAA) dos herbicidas, com e sem cobertura de palha da cana-de-açúcar (desdobramento da interação H x C significativa). JaboticabalSP, $2000 / 2001$

\begin{tabular}{|c|c|c|c|c|c|c|c|c|}
\hline \multirow{2}{*}{ Herbicida } & \multicolumn{4}{|c|}{ Cobertura do solo aos 45 DAA } & \multicolumn{4}{|c|}{ Cobertura do solo aos 90 DAA } \\
\hline & $(\% \mathrm{C})^{8 /}$ & com palha & sem palha & $(\% \mathrm{C})$ & $(\% \mathrm{C})^{8 /}$ & com palha & sem palha & $(\% \mathrm{C})$ \\
\hline $\begin{array}{l}\text { Trifloxysulfuron-sodium }+ \text { ametryne }^{1 / /} \\
\left(1.312,5 \mathrm{~g} \mathrm{ha}^{-1}\right)\end{array}$ & $(43,6)$ & b $224,6 \mathrm{~B}$ & bc $297,2 \mathrm{~A}$ & $(61,0)$ & $(41,4)$ & c $372,8 \mathrm{~A}$ & c $409,6 \mathrm{~A}$ & $(48,1)$ \\
\hline $\begin{array}{l}\text { Trifloxysulfuron-sodium }+ \text { ametryne } \\
\left(1.500 \mathrm{~g} \mathrm{ha}^{-1}\right)\end{array}$ & $(44,2)$ & bc $222,2 \mathrm{~A}$ & c $248,0 \mathrm{~A}$ & $(67,5)$ & $(41,3)$ & c $373,0 \mathrm{~A}$ & c $416,8 \mathrm{~A}$ & $(47,6)$ \\
\hline $\begin{array}{l}\text { Halosulfuron }^{2 /}+\text { surfatante }^{3 /} \\
\left(112,5 \mathrm{~g} \mathrm{ha}^{-1}+0,25 \%\right)\end{array}$ & $(87,6)$ & $49,2 \mathrm{~B}$ & d $117,4 \mathrm{~A}$ & $(84,6)$ & $(77,9)$ & d $140,0 \mathrm{~B}$ & c $344,6 \mathrm{~A}$ & $(56,4)$ \\
\hline $2,4-\mathrm{D}^{5 /}\left(1.675 \mathrm{~g} \mathrm{ha}^{-1}\right)$ & $(58,5)$ & bcd $165,2 \mathrm{~B}$ & b $331,8 \mathrm{~A}$ & $(56,5)$ & $(28,0)$ & $\mathrm{ab} 569,2 \mathrm{~A}$ & b $596,4 \mathrm{~A}$ & $(24,5)$ \\
\hline Sulfentrazone $^{6 /}\left(700 \mathrm{~g} \mathrm{ha}^{-1}\right)$ & $(68,0)$ & d $127,2 \mathrm{~A}$ & de $43,2 \mathrm{~B}$ & $(94,3)$ & $(35,9)$ & c $407,2 \mathrm{~A}$ & de $81,6 \mathrm{~B}$ & $(89,7)$ \\
\hline Imazapic $^{7 /}\left(105 \mathrm{~g} \mathrm{ha}^{-1}\right)$ & $(58,9)$ & bcd $163,4 \mathrm{~A}$ & d $111,6 \mathrm{~B}$ & $(85,4)$ & $(32,1)$ & bc $432,0 \mathrm{~A}$ & d $152,6 \mathrm{~B}$ & $(80,7)$ \\
\hline Testemunha infestada & $(0,0)$ & $398,0 \mathrm{~B}$ & a $762,4 \mathrm{~A}$ & $(0,0)$ & $(0,0)$ & a $636,0 \mathrm{~B}$ & a $790,6 \mathrm{~A}$ & $(0,0)$ \\
\hline Testemunha capinada & $(100,0)$ & $0,0 \mathrm{~A}$ & e $\quad 0,0 \mathrm{~A}$ & $(100,0)$ & $(100,0)$ & $0,0 \mathrm{~A}$ & $0,0 \mathrm{~A}$ & $(100,0)$ \\
\hline
\end{tabular}

${ }^{1 /}$ Krismat; ${ }^{2 /}$ Sempra; ${ }^{3 /}$ Aterbane; ${ }^{4 /}$ Daconate; ${ }^{5 /}$ Aminol; ${ }^{6 /}$ Boral; e ${ }^{7 /}$ Plateau; ${ }^{8 /}$ porcentagem de controle em relação à testemunha infestada.

Obs.: letras minúsculas no sentido das colunas comparam os herbicidas dentro de cada cobertura e letras maiúsculas no sentido das linhas comparam as coberturas dentro de cada herbicida.

A redução nas chances de sobrevivência das plântulas com pequenas quantidades de reservas nos diásporos (Pitelli \& Durigan, 2001) e a redução da amplitude térmica (Egley \& Duke, 1985; Velini \& Negrisoli, 2000), proporcionadas pelas coberturas mortas, não parecem ser as melhores teorias para explicar as reduções nas populações de tiririca. No entanto, a quantidade e a qualidade da luz que atravessa pelos interstícios da palha (Zimdahl, 1993) e a possibilidade de efeitos alelopáticos por substâncias produzidas e liberadas da palha (Lorenzi, 1993) podem constituir-se nas principais características relacionadas à redução.

As avaliações de controle mostram prejuízos ou benefícios à ação de certos herbicidas, em função da presença ou ausência de palha. Alguns deles, como o imazapic e o sulfentrazone, tiveram seu desempenho afetado pela presença da palha, em ambas as avaliações; contudo, foram os únicos a manterem controles superiores a $80 \%$, até 90 dias, quando na ausência desta. A mistura pronta, independentemente da dose, proporcionou controle regular, enquanto para o halosulfuron houve forte redução no controle com o passar do tempo, evidenciando sua ausência de efeito residual. Os fracos resultados da ação do 2,4D e do MSMA na primeira avaliação acentuaram-se na segunda. Nota-se que a ação inicial dos herbicidas aplicados em pós-emergência foi menos dependente da cobertura do solo.

A capacidade de um herbicida residual em atingir o solo, quando coberto por palha, não depende apenas da sua solubilidade em água, fotodecomposição e volatilização. A quantidade, a composição química e a origem da cobertura morta, assim como a quantidade e o período da primeira chuva ou irrigação ocorridas após a aplicação, além das condições climáticas prevalecentes durante e após, também podem ser fundamentais (Rodrigues, 1993).

O decréscimo na produção e brotação de tubérculos é o mais importante efeito do herbicida quando se considera o manejo desta planta daninha por um periodo maior (Durigan, 1991). Na Tabela 4 são apresentados os resultados da análise de variância para a quantidade e qualidade dos tubérculos coletados 60 dias após a aplicação dos herbicidas, em ambas as situações de cobertura do solo. Na Tabela 5 estão os desdobramentos das interações significativas para os números de tubérculos viáveis e inviáveis, respectivamente.

Planta Daninha, Viçosa-MG, v.22, n.1, p.127-135, 2004 
Tabela 4 - Análise de variância do número de tubérculos de tiririca em $0,027 \mathrm{~m}^{3}$ de solo e dos números de tubérculos viáveis, inviáveis e dormentes em 50 tubérculos, aos 60 dias após a aplicação dos herbicidas, além do teste (Tukey) de comparação das médias quando não houve interação significativa entre os fatores. Jaboticabal-SP, 2000/2001

\begin{tabular}{|c|c|c|c|c|c|}
\hline \multirow{3}{*}{\multicolumn{2}{|c|}{ Causa de variação }} & \multicolumn{4}{|c|}{ Valor de F } \\
\hline & & \multirow{2}{*}{$\begin{array}{c}\mathrm{N}^{\mathrm{Q}} \text { tubérculos/ } \\
0,027 \mathrm{~m}^{3}\end{array}$} & \multicolumn{3}{|c|}{$\mathrm{N}^{\circ}$ tubérculos/50 tub. } \\
\hline & & & Viáveis & Inviáveis & Dormentes \\
\hline \multicolumn{2}{|c|}{ Herbicidas (H) } & $\ldots, 40 * * \ldots$ & $47,0^{* *}$ & $81,6^{* *}$ & $0,78^{\text {ns }}$ \\
\hline \multicolumn{2}{|c|}{ Cobertura (C) } & $125,68^{* *}$ & $175,37 * *$ & $66,62^{* *}$ & $147,56^{* *}$ \\
\hline \multicolumn{2}{|c|}{ Herb. $x$ Cob. $(\mathrm{H} \times \mathrm{C})$} & $1,40^{\mathrm{ns}}$ & $17,99 * *$ & $13,05^{* *}$ & $1,48^{\mathrm{ns}}$ \\
\hline \multicolumn{2}{|c|}{ CV $(\%)$} & $24,7(\mathrm{H}) 21,8(\mathrm{C})$ & $10,5(\mathrm{H}) \quad 11,7(\mathrm{C})$ & $22,1(\mathrm{H}) 30,5(\mathrm{C})$ & $24,9(\mathrm{H}) \quad 25,3(\mathrm{C})$ \\
\hline \multicolumn{2}{|c|}{ Trifloxysulfuron-sodium +ametryne ${ }^{1 /}\left(1,312,5 \mathrm{~g} \mathrm{ha}^{-1}\right)$. } & $\ldots 294,2 \mathrm{bc} \ldots \ldots$ & & & $8,3 \mathrm{a}$ \\
\hline \multicolumn{2}{|c|}{ Trifloxysulfuron-sodium + ametryne $\left(1.500 \mathrm{~g} \mathrm{ha}^{-1}\right)$} & $235,9 \mathrm{c}$ & & & 7.5- \\
\hline \multicolumn{2}{|c|}{ 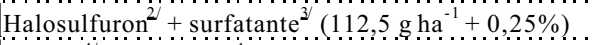 } & 3099 abc & & & 6,8 a \\
\hline \multicolumn{2}{|c|}{ 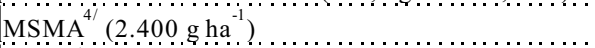 } & $368,5 \mathrm{ab}$ & & & 7,2 a \\
\hline \multicolumn{2}{|c|}{$2,4-D^{5}\left(1.675 \mathrm{~g} \mathrm{ha}^{-1}\right)$} & $\begin{array}{l}416,1 \mathrm{ab} \\
244,4 \mathrm{c}\end{array}$ & & & $\begin{array}{l}6,9 \mathrm{a} \\
7,6 \mathrm{a}\end{array}$ \\
\hline \multicolumn{2}{|c|}{ Imazapic $^{7 /}\left(105 \mathrm{~g} \mathrm{ha}^{-1}\right)$} & $312,2 \mathrm{abc}$ & & & $7,4 \mathrm{a}$ \\
\hline \multicolumn{2}{|c|}{ Testemunha infestada } & $421,3 \mathrm{a}$ & & & 8,0 a \\
\hline \multicolumn{2}{|c|}{ Testemunha capinada } & $401,4 \mathrm{ab}$ & & & $8,1 \mathrm{a}$ \\
\hline \multicolumn{2}{|l|}{ dms a $5 \%$} & 122,8 & & & 2,8 \\
\hline \multirow{2}{*}{ Cobertura } & com palha & $2478 \mathrm{~B}$ & & & $5,1 \mathrm{~B}$ \\
\hline & sem palha & $419,7 \mathrm{~A}$ & & & $10,0 \mathrm{~A}$ \\
\hline \multicolumn{2}{|l|}{ dms a $5 \%$} & 31,1 & & & 0,8 \\
\hline
\end{tabular}

Tabela 5 - Médias do número de tubérculos viáveis e inviáveis de tiririca por 50 tubérculos, 60 dias após a aplicação dos herbicidas, com e sem cobertura de palha da cana-de-açúcar (desdobramento da interação H x C significativa). JaboticabalSP, $2000 / 2001$

\begin{tabular}{|c|c|c|c|c|c|c|c|c|}
\hline \multirow{2}{*}{ Herbicida } & \multicolumn{4}{|c|}{ Cobertura do solo para tubérculos viáveis } & \multicolumn{4}{|c|}{ Cobertura do solo para tubérculos inviáveis } \\
\hline & $(\% \mathrm{C})^{8 /}$ & com palha & sem palha & $(\% \mathrm{C})$ & $(\% \mathrm{C})^{8 /}$ & com palha & sem palha & $(\% \mathrm{C})$ \\
\hline $\begin{array}{l}\text { Trifloxysulfuron-sodium + ametryne } \\
\left(1.312,5 \mathrm{~g} \mathrm{ha}^{-1}\right)\end{array}$ & $(69,2)$ & bcd $34,6 \mathrm{~A}$ & c $12,8 \mathrm{~B}$ & $(25,6)$ & $(19,2)$ & bc $9,6 \mathrm{~B}$ & a $26,4 \mathrm{~A}$ & $(52,8)$ \\
\hline $\begin{array}{l}\text { Trifloxysulfuron-sodium + ametryne } \\
\left(1.500 \mathrm{~g} \mathrm{ha}^{-1}\right)\end{array}$ & $(73,2)$ & abcd $36,6 \mathrm{~A}$ & c $11,4 \mathrm{~B}$ & $(22,8)$ & $(18,8)$ & bc $9,4 \mathrm{~B}$ & a $27,6 \mathrm{~A}$ & $(55,2)$ \\
\hline $\begin{array}{l}\text { Halosulfuron }^{2 /}+\text { surfatante }^{3 /} \\
\left(112,5 \mathrm{~g} \mathrm{ha}^{-1}+0,25 \%\right)\end{array}$ & $(49,6)$ & $24,8 \mathrm{~A}$ & b $22,4 \mathrm{~A}$ & $(44,8)$ & $(39,2)$ & a $19,6 \mathrm{~A}$ & b $19,4 \mathrm{~A}$ & $(38,8)$ \\
\hline $2,4 \mathrm{D}^{5 /}\left(1.675 \mathrm{~g} \mathrm{ha}^{-1}\right)$ & $(82,8)$ & $41,4 \mathrm{~A}$ & a $37,4 \mathrm{~A}$ & $(74,8)$ & $(7,2)$ & c $3,6 \mathrm{~A}$ & c $3,8 \mathrm{~A}$ & $(7,6)$ \\
\hline Sulfentrazone $\mathrm{e}^{6 /}\left(700 \mathrm{~g} \mathrm{ha}^{-1}\right)$ & $(66,4)$ & $33,2 \mathrm{~A}$ & c $14,8 \mathrm{~B}$ & $(29,6)$ & $(24,8)$ & b $12,4 \mathrm{~B}$ & a $26,4 \mathrm{~A}$ & $(52,8)$ \\
\hline Imazapic $^{7 /}\left(105 \mathrm{~g} \mathrm{ha}^{-1}\right)$ & $(74,8)$ & abcd $37,4 \mathrm{~A}$ & b $25,4 \mathrm{~B}$ & $(50,8)$ & $(15,6)$ & bc $7,8 \mathrm{~B}$ & b $14,6 \mathrm{~A}$ & $(29,2)$ \\
\hline Testemunha infestada & $(83,2)$ & a $\quad 41,6 \mathrm{~A}$ & a $36,4 \mathrm{~B}$ & $(72,8)$ & $(6,8)$ & $3,4 \mathrm{~A}$ & $2,6 \mathrm{~A}$ & $(5,2)$ \\
\hline Testemunha capinada & $(79,6)$ & abc $39,8 \mathrm{~A}$ & a $36,8 \mathrm{~A}$ & $(73,6)$ & $(7,2)$ & $3,6 \mathrm{~A}$ & $3,6 \mathrm{~A}$ & $(7,2)$ \\
\hline
\end{tabular}

${ }^{1 /}$ Krismat; ${ }^{2 /}$ Sempra; ${ }^{3 /}$ Aterbane; ${ }^{4 /}$ Daconate; ${ }^{5 /}$ Aminol; ${ }^{6 /}$ Boral; e ${ }^{2 /}$ Plateau; ${ }^{8 /}$ porcentagem em relação a 50 tubérculos.

Obs.: letras minúsculas no sentido das colunas comparam os herbicidas dentro de cada cobertura e letras maiúsculas no sentido das linhas comparam as coberturas dentro de cada herbicida.

Foram constatadas reduções (40,9\%) significativas no número de tubérculos com a presença da palha. Os bons niveis de controle impostos pelo herbicida sulfentrazone repercutiram na formação de tubérculos. Para a mistura de trifloxysulfuron-sodium + ametryne, apesar das reduções apenas regulares (41-67\%) nos números de manifestações 
epígeas, é importante ressaltar as menores produções de tubérculos pelas plantas afetadas, atingindo 30,2 e 44,0\% de redução em relação à testemunha, com as doses de $1.312,5$ e $1.500 \mathrm{~g} \mathrm{ha}^{-1}$, respectivamente. Para este herbicida e onde não houve cobertura com palha, também foram constatadas reduções significativas e até superiores às do sulfentrazone no número de tubérculos viáveis, ao mesmo tempo em que também foram superiores os percentuais de tubérculos inviáveis. Algumas possibilidades podem ser relacionadas para esse bom desempenho da mistura em termos de redução dessas estruturas de reprodução das plantas de tiririca: a) ação sistêmica do herbicida a partir de sua absorção pela parte aérea; b) redução geral no acúmulo de carboidratos pela planta, com reflexos na formação de novos tubérculos; c) ação conjunta de parte do herbicida absorvido pelas folhas, com parte dele descendo no perfil do solo e sendo absorvido diretamente por essas estruturas em formação ou brotação. A terceira hipótese parece ser a mais viável e ajuda a explicar os piores resultados obtidos quando havia cobertura morta no solo. Os percentuais de tubérculos inviáveis (dentre os 50 separados ao acaso) foram de 52,8 e $55,2 \%$ para as doses de $1.312,5$ e $1.500 \mathrm{~g} \mathrm{ha}^{-1}$ da mistura, respectivamente, onde não havia palha. Esses percentuais foram de 38,8, 14,4, 7,6 e 29,2\% para os herbicidas halosulfuron, MSMA, 2,4-D e imazapic, respectivamente. Apenas o sulfentrazone proporcionou redução semelhante $(52,8 \%)$ às evidenciadas para a mistura de trifloxysulfuron-sodium + ametryne.

O número de tubérculos dormentes não foi afetado pela ação dos herbicidas (Tabela 4), corroborando as afirmações de Thullen \& Keeley (1975), de que esta é uma característica difícil de ser alterada pela ação de herbicidas.

As diferenças estatisticamente significativas na altura das plantas até a última aurícula visível e no número de afilhos, detectadas aos 65 DAA, devem-se mais à interferência das plantas remanescentes do controle do que a efeitos fitotóxicos dos herbicidas (Tabela 6). As

Tabela 6 - Análise de variância da altura das plantas de cana-de-açúcar até a última aurícula visível e do número de afilhos em $6 \mathrm{~m}$ aos 65 dias após a aplicação dos herbicidas; e do número, diâmetro, comprimento dos internódios e produção de colmos da cana-de-açúcar por ocasião da colheita, além do teste (Tukey) de comparação das médias, quando não houve interação significativa entre os fatores. Jaboticabal-SP, 2000/2001

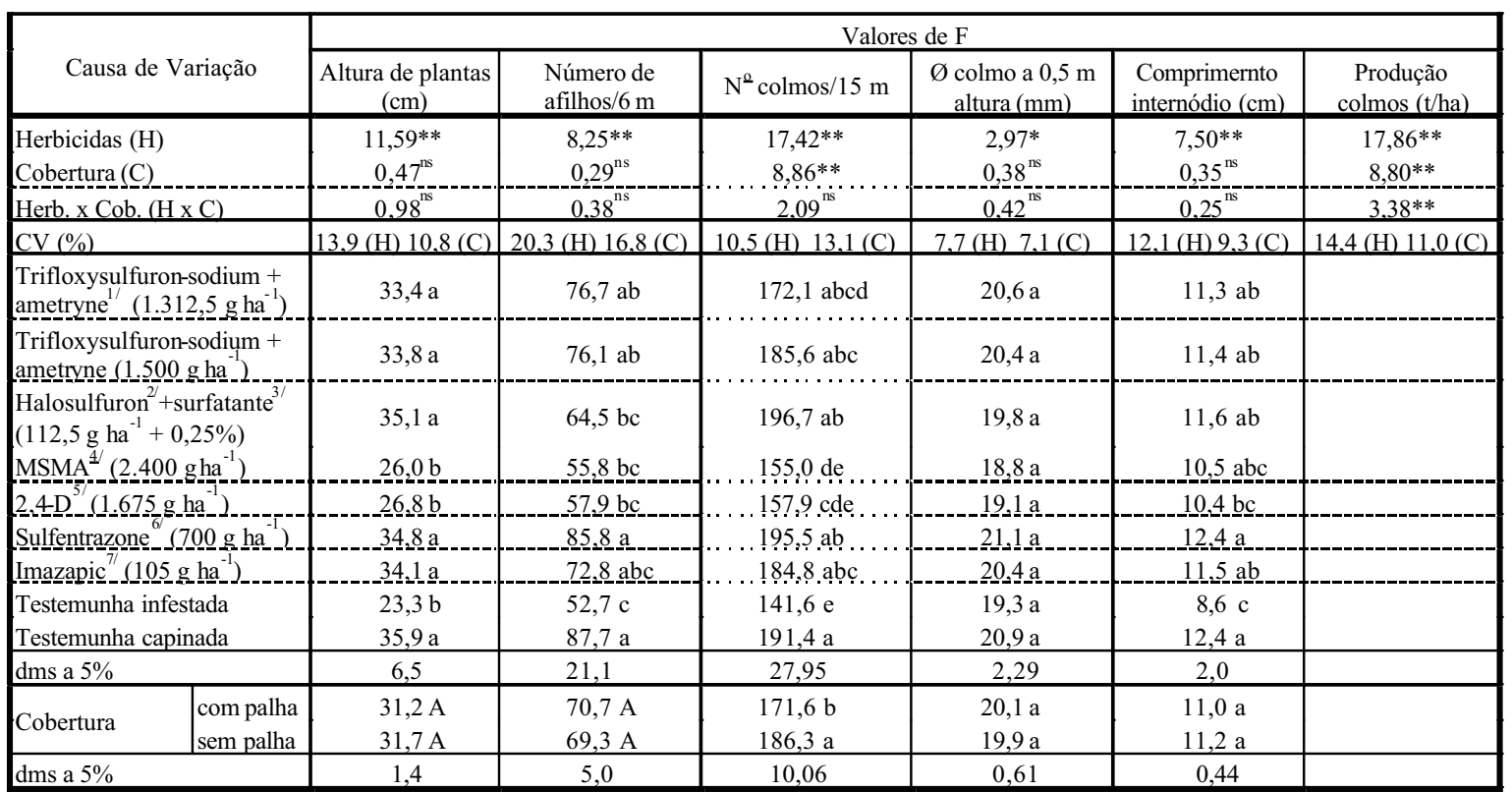

${ }^{1 /}$ Krismat; ${ }^{2 /}$ Sempra; ${ }^{3 /}$ Aterbane; ${ }^{4 /}$ Daconate; ${ }^{5 /}$ Aminol; ${ }^{6 /}$ Boral; e ${ }^{\text {Z/ }}$ Plateau.

Obs.: letras minúsculas no sentido das colunas comparam os herbicidas dentro de cada cobertura e letras maiúsculas no sentido das linhas comparam as coberturas dentro de cada herbicida. 
médias de altura foram reduzidas em 35,1 , 25,3 e $27,6 \%$ nas parcelas da testemunha infestada e nas tratadas com 2,4-D e MSMA, respectivamente. O número de afilhos da cana é ainda mais suscetivel, e os herbicidas que proporcionaram brotações estatisticamente iguais à da testemunha capinada foram sulfentrazone, imazapic e a mistura, em ambas as doses.

Como conseqüência do efeito negativo na brotação inicial, também foram constatadas reduções significativas no número de colmos, por ocasião da colheita, nos tratamentos em que a pressão de interferência continuou acentuada por todo o ciclo, como pode ser observado pela análise de variância da Tabela 6 . Da mesma forma, o comprimento dos internódios da base da planta refletem o estresse sentido por ela. Por outro lado, não houve diferenças entre os tratamentos no diâmetro dos colmos a 0,50 m de altura.

O desdobramento da interação significativa entre herbicidas e cobertura do solo para as médias de produtividade de colmos da cana é apresentado na Tabela 7 . As diferenças na produtividade entre as testemunhas foram de 36,8 e $41,3 \%$ para as áreas com e sem palha, respectivamente. Essa informação constituise em subsídio para não se aceitar a cobertura de palha como solução única no manejo desta planta daninha. As maiores produções de colmos, na ausência de palha, foram garantidas pelos herbicidas sulfentrazone, imazapic, halosulfuron e a mistura na dose menor. É importante ressaltar que, apesar de não diferentes estatisticamente, os resultados obtidos com a mistura em ambas as doses e imazapic, nestas condições, não permitem garantir que os potenciais de produtividade de variedades de cana serão plenos, em função dos controles que proporcionam. No entanto, onde a palha não foi mantida, esta afirmação é possível para os quatro herbicidas mencionados.

Os resultados das análises tecnológicas (Brix, Pol caldo e cana, Acidez, Fibra, Pureza e ATR) realizadas nos colmos da cana não mostraram diferenças significativas entre os tratamentos herbicidas e pela presença ou ausência da cobertura vegetal, razão pela qual não foram apresentados. Vários pesquisadores já evidenciaram a dificuldade de alterações qualitativas (Durigan, 1991; Seraphim, 1994), não obstante terem sido constatadas grandes diferenças no acúmulo de açúcar por área em função de reduções nos teores e na produção

Tabela 7 - Médias da produtividade de colmos na colheita de cana-de-açúcar, em $\mathrm{tha}^{-1}$, face do controle químico da tiririca nas áreas com e sem cobertura de palha da cana-de-açúcar (desdobramento da interação H x C significativa). JaboticabalSP, 2000/2001

\begin{tabular}{|c|c|c|}
\hline \multirow{2}{*}{ Herbicida } & \multicolumn{2}{|c|}{ Cobertura do solo } \\
\hline & com palha & sem palha \\
\hline Trifloxysulfuron-sodium + ametryne $\mathrm{e}^{1 /}\left(1.312,5 \mathrm{~g} \mathrm{ha}^{-1}\right)$ & abc $57,6 \mathrm{~B}$ & $\mathrm{ab} \quad 72,0 \mathrm{~A}$ \\
\hline Trifloxysulfuron-sodium + ametryne $\left(1.500 \mathrm{~g} \mathrm{ha}^{-1}\right)$ & bc $51,8 \mathrm{~B}$ & b $\quad 64,5 \mathrm{~A}$ \\
\hline Halosulfuron $^{2 /}+$ surfatante $^{3 /}\left(112,5 \mathrm{~g} \mathrm{ha}^{-1}+0,25 \%\right)$ & $\mathrm{ab} \quad 65,1 \mathrm{~A}$ & bcd $60,2 \mathrm{~A}$ \\
\hline $\operatorname{MSMA}^{4 /}\left(2.400 \mathrm{~g} \mathrm{ha}^{-1}\right)$ & c $\quad 46,8 \mathrm{~A}$ & cde $48,7 \mathrm{~A}$ \\
\hline $2,4-\mathrm{D}^{5 /}\left(1.675 \mathrm{~g} \mathrm{ha}^{-1}\right)$ & c $\quad 44,7 \mathrm{~A}$ & de $44,9 \mathrm{~A}$ \\
\hline Sulfentrazone ${ }^{6 /}\left(700 \mathrm{~g} \mathrm{ha}^{-1}\right)$ & a $68,6 \mathrm{~B}$ & a $81,2 \mathrm{~A}$ \\
\hline Imazapic $^{7 /}\left(105 \mathrm{~g} \mathrm{ha}^{-1}\right)$ & abc $58,5 \mathrm{~A}$ & bc $64,0 \mathrm{~A}$ \\
\hline Testemunha infestada & c $\quad 45,4 \mathrm{~A}$ & e $\quad 41,2 \mathrm{~A}$ \\
\hline Testemunha capinada & $71,8 \mathrm{~A}$ & $70,2 \mathrm{~A}$ \\
\hline & \multicolumn{2}{|c|}{ dms para herbicidas dentro de coberturas $=15,33$} \\
\hline & \multicolumn{2}{|c|}{ dms para coberturas dentro de herbicidas $=8,33$} \\
\hline
\end{tabular}

\footnotetext{
1/ Krismat; ${ }^{2 /}$ Sempra; ${ }^{3 /}$ Aterbane $;{ }^{4 /}$ Daconate; ${ }^{5 /}$ Aminol; ${ }^{6 /}$ Boral; e ${ }^{7 /}$ Plateau.
}

Obs.: letras minúsculas no sentido das colunas comparam os herbicidas dentro de cada cobertura e letras maiúsculas no sentido das linhas comparam as coberturas dentro de cada herbicida. 
de colmos (Arevalo et al., 1974; Wang et al., 1978). Keeley (1987) relacionou grande número de trabalhos científicos, em diferentes condições, que constataram reduções de 0 a $45 \%$ na produção de colmos de cana-de-açúcar quando ela esteve associada à tiririca em parte ou no total do seu ciclo. Os dados obtidos na presente pesquisa reforçam essa afirmação.

\section{LITERATURA CITADA}

AREVALO, R. A. Plantas daninhas da cana-de-açúcar. Araras: IAA/PLANALSUCAR - CONESUL, 1979. $46 \mathrm{p}$.

AREVALO, R. A.; CERRIZUELLA, E. A.; SOLDATI, A. A. Competência de malezas específicas em caña planta. I Cyperus rotundus L. Malezas y control (ASAM), v. 3, n. 1, p. 59-75, 1974.

DELOUCHE, J. C. et al. The tetrazolium test for seed viability. Miss. Agric. For. Exp. Staf. Tech. Bull., v. 51, p. $1-63,1962$

DURIGAN, J. C. Manejo da tiririca (Cyperus rotundus L.) antes e durante a implantação da cultura de cana-deaçúcar (Saccharum spp.). 1991. 336 f. Tese (LivreDocência) - Universidade Estadual de São Paulo, Jaboticabal, 1991.

EGLEY, G. H.; DUKE, S. Physiology of weed seed dormancy and germination. In: DUKE, S. O. Weed Physiology. I - Reproduction and ecophysiology. Florida: CRC Press, 1985. p. 27-64.

EUROPEAN WEED RESEARCH COUNCIL - EWRC. Report of the $3^{\text {rd }}$ and $4^{\text {th }}$ meetings of EWRC - Comittee of Methods in Weed Research. Weed Res., v. 4, n. 1, p. 88, 1964.

FORNAROLLI, B. N.; RODRIGUES, J. L.; VALÉRIO, M. A. Influência da cobertura morta no comportamento do herbicida atrazine. Planta Daninha, v. 16, n. 2, p. 97-107, 1998.
KEELEY, P. E. Interference and interaction of purple and yellow nutsedges (C. rotundus and $C$. esculentus) with crops. Weed. Technol., v. 1, n. 1, p. 74-81, 1987.

LORENZI, H. Efeito da palha da cana no controle das plantas daninhas. In: CONGRESSO BRASILEIRO DE HERB. E PLANTAS DANINHAS, 19., 1993, Londrina. Resumos... Londrina: 1993. p. 28-29.

MARTINS, D. et al. Emergência em campo de dicotiledôneas infestantes em solo coberto com palha de cana-de-açúcar. Planta Daninha, v. 17, n. 1, p. 151-161, 1999.

PITELLI, R. A.; DURIGAN, J. C. Ecologia das plantas daninhas no sistema de plantio direto. In: DIAZ ROSSELLO, R. (Coord.) Siembra directa en Cone Sur. Montevideo: PROCISUR, 2001. p. 203-210.

RODRIGUES, B. N. Influência da cobertura morta no comportamento dos herbicidas imazaquin e clomazone. Planta Daninha, v. 11, n. 1, p. 21-28, 1993.

SERAPHIM, R. C. Eficácia para o controle de tiririca (Cyperus rotundus $\mathrm{L}$.) e seletividade para as plantas de cana-de-açúcar (Saccharum spp.), do herbicida halosulfuron aplicado em pós-emergência. Jaboticabal: Universidade Estadual de São Paulo, 1994. 74 p. (Trabalho de Graduação)

THULLEN, R. J.; KEELEY, P. E. Yellow nutsedge sprouting and resprouting potential. Weed Sci., v. 23, n. 4, p. $333-337,1975$.

VELINI, E.D.; NEGRISOLI, E. Controle de plantas daninhas em cana crua. In: CONGRESSO BRASILEIRO DA CIÊNCIA DAS PLANTAS DANINHAS, 22., Foz do Iguaçu, 2000. Palestras... Foz do Iguaçu: 2000. p. 148-164.

WANG, J. I.; TWU, T. L.; PEG, C. S. Ecological studies on main weed species in cane fields of Taiwan. Rep. Taiwan Sugar Res. Inst., v. 81, p. 1-10, 1978.

ZIMDAHL, R. L. Fundamentals of weed science. New York: Academic Press, 1993. 450 p. 